\title{
Las sociedades cooperativas y su obligatoriedad ante el Instituto Mexicano del Seguro Social
}

\author{
Araceli del Carmen Beristain Apreza ${ }^{1}$ \\ Universidad Autónoma del Estado de México (UAEMex)
}

Sumario: I. Marcos jurídico constitucional y legal regulatorios de las sociedades cooperativas en México. II. Aspectos descriptivos de las Sociedades Cooperativas en la legislación nacional sobre la materia. III. Las Sociedades Cooperativas y su obligatoriedad ante el Instituto Mexicano del Seguro Social (IMSS). IV. Conclusiones. V. Fuentes de consulta.

Resumen: Como la economía de toda nación depende de aquellos que constituyen su fuerza de trabajo o mano de obra, es dable atribuir que parte de ella se conforma a través de las sociedades cooperativas, agrupaciones que en su naturaleza tienen como fin la satisfacción de necesidades tanto individuales, como colectivas, mismas que se hacen alcanzables a través de la realización de actividades económicas de producción, distribución y consumo, de bienes y servicios. De ahí la inquietud por analizar primeramente, el marco constitucional y legal de la rectoría económica del Estado mexicano de la cual participan desde luego las Sociedades Cooperativas; en segundo término, el marco legal de las

1 Maestra en Estudios Jurídicos por la Facultad de Derecho de la Universidad Autónoma del Estado de México (UAEMex) ; Especialista en Derecho Legislativo por el Instituto de Estudios Legislativos del Poder Legislativo del Estado de México; Diplomada en Derecho de la Seguridad Social, Derecho del Trabajo, Derecho Procesal del Trabajo por el Colegio de Estudios Jurídicos de México (CEJUM), y en Derecho Fiscal e Impuestos por la Facultad de Contaduría y Administración de la Universidad Autónoma del Estado de México (UAEMex). Catedrático de asignatura de la Facultad de Derecho, de la Universidad Autónoma del Estado de México en las áreas de derecho del trabajo, derecho de la seguridad social, proceso laboral y proceso administrativo; así como de la Facultad de Contaduría y Administración de la UAEMex en las unidades de aprendizaje de derecho laboral, fundamentos de derecho, recursos para contribuyentes, contribuciones de personas físicas y morales, así como de seguridad social e impuestos especiales. Representante legal del Instituto Mexicano del Seguro Social (IMSS), Jefe del Departamento Contencioso Administrativo de la Subdirección Jurídica del Instituto Mexiquense de la Vivienda Social, del Gobierno del Estado. Abogado postulante en las áreas de: civil, fiscal, laboral y seguridad social. 
Sociedades Cooperativas, a través de un estudio de su carácter mercantil; y finalmente, en un tercer apartado, el marco jurídico de los esquemas de seguridad y previsión social de la que participan estas agrupaciones.

Palabras clave: economía, cooperativismo, cooperativa, necesidad, bienes, servicios.

Abstract: as the economy of every nations depends on those who make up its workforce or labor force, it is possible to attribute that part of it is formed thorough cooperative societies, groups that in their nature have as their purpose the satisfaction of both individual needs, as collectives, which are made achievable through the performance of economic activities of production, distribution and consumption, of goods and services. Hence the concern to analyze first the constitutional and legal framework of the economic stewardship of the Mexican State in which Cooperative Societies participate, of course, second, the legal framework of Cooperative Societies, thorough a study of their commercial nature; and finally, in a third section, the legal framework of the Social Security and welfare schemes in which these groups participate.

Keywords: economy, cooperativism, cooperative, needs, goods, services. 


\section{Marcos jurídico constitucional y legal regulatorios de las Sociedades Cooperativas en México}

Es un hecho conocido el que la economía de una nación dependa en gran medida de la fuerza de trabajo, sin embargo, situaciones como la inequitativa distribución de la riqueza, el aumento del empobrecimiento de las familias y la falta de oportunidades, han propiciado consecuentemente, elevados costos sociales ante la ausencia de desarrollo de un importante porcentaje de la población.

Es por ello, que aunque el término trabajo haya asumido múltiples concepciones a lo largo de la historia, abarcando acepciones como la filosófica, la fisiológica, la mecánica, la jurídica, la política, la social o teleológica, y la económica; todas estas nociones van a depender de la postura o perspectiva en que el concepto de trabajo sea analizado, importando para este proyecto y apartado, las tres últimas connotaciones.

Lo anterior, toda vez que el trabajo desde el ángulo político, «es objeto de la actividad legisladora y de la función rectora de la administración pública, con fines de protección para los trabajadores, de mantenimiento de la paz social y del incremento productor» (CABANELLAS, 1968: 90); además de que la concepción social del trabajo, se entrelaza con su aspecto teleológico, es decir, que este debe servir al hombre para satisfacer sus necesidades; y finalmente, en lo económico, el trabajo es considerado como un factor de producción, el cual supone un intercambio de bienes y servicios para la satisfacción de las necesidades humanas.

Todos estos aspectos, demuestran que las sociedades cooperativas se han conformado Constitucionalmente, al menos dentro del Estado mexicano, como fuente de la economía nacional y de apertura de empleos, lo cual tiene su razón de ser a partir del contenido del artículo 25 Constitucional, al prever que:

Corresponde al Estado la rectoría del desarrollo nacional para garantizar que éste sea integral y sustentable, que fortalezca la Soberanía de la Nación y su régimen democrático y que, mediante la competitividad, el fomento del crecimiento económico y el empleo, y una más justa distribución del ingreso y la riqueza, permita el pleno ejercicio de la libertad y la dignidad de los individuos, grupos y clases sociales, cuya seguridad protege esta Constitución. La competitividad se entenderá como el conjunto de condiciones necesarias para generar un mayor crecimiento económico, promoviendo la inversión y la generación de empleo.

El Estado planeará, conducirá, coordinará y orientará la actividad económica nacional, y llevará a cabo la regulación y fomento de las actividades que demande el interés general en el marco de libertades que otorga esta Constitución. 
Al desarrollo económico nacional concurrirán, con responsabilidad social, el sector público, el sector social y el sector privado, sin menoscabo de otras formas de actividad económica que contribuyan al desarrollo de la Nación.

El sector público tendrá a su cargo, de manera exclusiva, las áreas estratégicas que se señalan en el Artículo 28, párrafo cuarto de la Constitución, manteniendo siempre el Gobierno Federal la propiedad y el control sobre los organismos que en su caso se establezcan.

Asimismo podrá participar por sí o con los sectores social y privado, de acuerdo con la ley, para impulsar y organizar las áreas prioritarias del desarrollo.

Bajo criterios de equidad social y productividad se apoyará e impulsará a las empresas de los sectores social y privado de la economía, sujetándolos a las modalidades que dicte el interés público y al uso, en beneficio general, de los recursos productivos, cuidando su conservación y el medio ambiente.

La ley establecerá los mecanismos que faciliten la organización y la expansión de la actividad económica del sector social: de los ejidos, organizaciones de trabajadores, cooperativas, comunidades, empresas que pertenezcan mayoritaria o exclusivamente a los trabajadores $y$, en general, de todas las formas de organización social para la producción, distribución y consumo de bienes y servicios socialmente necesarios.

La ley alentará y protegerá la actividad económica que realicen los particulares y proveerá las condiciones para que el desenvolvimiento del sector privado contribuya al desarrollo económico nacional, promoviendo la competitividad e implementando una política nacional para el desarrollo industrial que incluya vertientes sectoriales y regionales, en los términos que establece esta Constitución. (CONSTITUCIÓN POLÍTICA DE LOS ESTADOS UNIDOS MEXICANOS).

Destacando de ello, la aceptación que hace el Estado de la figura de la sociedad cooperativa, al considerarla como una forma de organización social para el trabajo que permite la producción, distribución y consumo de bienes y servicios, así como la apertura de fuentes de trabajo.

Así mismo, el párrafo octavo del artículo 28 de la Constitución Política de los Estados Unidos Mexicanos, si bien establece la prohibición de los monopolios y de las prácticas monopólicas, también señala que:

No constituyen monopolios las asociaciones de trabajadores formadas para proteger sus propios intereses y las asociaciones o sociedades cooperativas de productores para que, en defensa de sus intereses o del interés general, vendan directamente en los mercados extranjeros los productos nacionales o industriales que sean la principal fuente de riqueza de la región en que se produzcan o que no sean artículos de pri- 
mera necesidad, siempre que dichas asociaciones estén bajo vigilancia o amparo del Gobierno Federal o de los Estados, y previa autorización que al efecto se obtenga de las legislaturas respectivas en cada caso. Las mismas Legislaturas, por sí o a propuesta del Ejecutivo podrán derogar, cuando así lo exijan las necesidades públicas, las autorizaciones concedidas para la formación de las asociaciones de que se trata. ... (Idem)

De esta manera, el Estado mexicano ha dado paso a la conformación de agrupaciones de trabajadores a través de la estructuración y regulación de sociedades cooperativas, como instrumentos que permitan incentivar la productividad, la creación de nuevas empresas tales como algunas Pequeñas y Medianas Empresas (PYMES) y la comercialización hacia el exterior de los productos nacionales, propiciando desde luego aumentos en la economía del país, además de otorgar a sus socios y trabajadores la posibilidad de obtener ingresos salariales, y de contar con protección en materia de trabajo y de seguridad social.

Por su parte, el artículo 123, apartado A), fracción XXX de la Constitución Federal, establece que: «Toda persona tiene derecho al trabajo digno y socialmente útil; al efecto, se promoverán la creación de empleos y la organización social del trabajo conforme a la ley. A... XXX. Asimismo serán consideradas de utilidad social, las sociedades cooperativas para la construcción de casas baratas e higiénicas, destinadas a ser adquiridas en propiedad, por los trabajadores en plazos determinados...» (Idem).

Dicho apartado guarda relación con el contenido del artículo $2 .^{\circ}$ de la Ley General de Sociedades Cooperativas (LGSC), toda vez que el propósito de cualquier sociedad cooperativa, se encamina a la satisfacción de necesidades individuales y colectivas, haciendo uso de la práctica de diferentes actividades económicas, tales como la producción, distribución y consumo de bienes y servicios, que para este caso específico, se alude a la adquisición de casas habitación.

Finalmente, el marco legal que regula a las sociedades cooperativas dentro de México queda comprendido: primeramente, por la Ley General de Sociedades Cooperativas (LGSC); en segundo término y de manera supletoria la Ley General de Sociedades Mercantiles (LGSM), tal como lo se señala en el contenido del artículo $10 .^{\circ}$ de la primera Ley citada en este párrafo2; así como de manera complementaria, la Ley

2 El artículo 10 de la Ley General de Sociedades Cooperativas establece que, «las sociedades que simulen constituirse en sociedades cooperativas o usen indebidamente las denominaciones alusivas a las mismas, serán nulas de pleno derecho y estarán sujetas a las sanciones que establezcan las leyes respectivas». 
para Regular las Actividades de las Sociedades Cooperativas de Ahorro y Préstamo, y la Ley de Ahorro y Crédito Popular, por cuanto hace a las sociedades cooperativas con actividades de ahorro y préstamo; además del Código Fiscal de la Federación, la Ley del Impuesto sobre la renta (LISR), la Ley del Impuesto al Valor Agregado (LIVA), y la Ley del Seguro Social (LSS), por cuanto hace a su régimen fiscal y de seguridad social respectivamente.

\section{Aspectos descriptivos de las Sociedades Cooperativas en la legislación nacional sobre la materia}

Dentro de este apartado, se pretenden establecer de manera muy general los elementos que sirven para describir a las sociedades cooperativas, tomando como base los ordenamientos jurídicos que la regulan, para lo cual se explicarán de forma breve su conceptualización, su clasificación, los requisitos para su constitución, su régimen económico, en cuanto hace a los aportes y participaciones de cada uno de los socio, así como su sistema fiscal, por cuanto refriere al pago de las aportaciones de seguridad social y demás impuestos a que se encuentren obligados cumplimentar; aunado al análisis de su estructura y administración, los derechos y obligaciones de los socios, además de su disolución y la forma en que deberán dar cumplimiento a su liquidación, entre otros puntos.

\subsection{Conceptualización, objetivos, principios de las Sociedades Cooperativas}

Para ello, en primer término, la Ley General de Sociedades Mercantiles reconoce dentro de su artículo $1 .^{\circ}$ a las sociedades cooperativas como una especie de sociedad mercantil, las cuales estarán sometidas al marco regulatorio de su ley especializada y de la ley en comento de manera supletoria, además de todas aquellas disposiciones fiscales y de seguridad social aplicables, ya referidas en el párrafo último del anterior apartado.

Bajo esta tesitura, el artículo 2..$^{\circ}$ de la Ley General de Sociedades Cooperativas enmarca que «la sociedad cooperativa es una forma de organización social integrada como mínimo por cinco personas físicas, que unidos con base en intereses comunes y en los principios de solidaridad, esfuerzo propio y ayuda mutua, con el propósito de satisfacer necesidades individuales y colectivas, a través de la realización de acti- 
vidades económicas de producción, distribución y consumo de bienes y servicios». (LEY GENERAL DE SOCIEDADES COOPERATIVAS)

Lo cual indica que los objetivos que toda sociedad cooperativa debe buscar:

a) Económicos

- Mejorar los niveles de ingreso y bienestar social de los socios y sus familias.

- Obtener crecientes niveles de vida, por la vía del trabajo productivo.

— La práctica de actividades económicas lícitas. (artículo 8. LGSC).

b) Sociales

— Fomentar, promover y desarrollar las capacidades, actitudes, aptitudes, habilidades y destrezas de los socios, por medio de la educación y capacitación, calificando su fuerza de trabajo.

- Poner en práctica el fondo de educación cooperativa (artículo 59 LGSC).

- Desarrollar el espíritu de cooperación, ayuda mutua, solidaridad y democracia. (ONG CONTRALORÍA CIUDADANA PARA LA RENDICIÓN DE CUENTAS, A.C., 2009: 6).

De esa manera dentro de las actividades lícitas que pueden desarrollar las sociedades cooperativas encontramos:

- Impulsar el autoempleo y empleo colectivo.

- Impulsar el Turismo rural en las zonas indígenas.

- Recibir y proporcionar servicios profesionales de asistencia técnica, asesoría, consultoría y capacitación.

- Promover, impulsar y apoyar procesos de organización en grupos urbanos y rurales.

- Organizar, impulsar y realizar cursos, orientados a la organización social y económica de grupos y organizaciones del campo.

- Asesoría, elaboración y ejecución de actividades didácticas para la obtención de objetivos sociales.

- Producción, compra, venta, almacenamiento, transformación, distribución, representación, comisión, consignación, importación y exportación de toda clase de bienes, productos naturales, artesanías, materias prima, productos de origen vegetal, mineral, animal y los derivados de los mismos.

- Servicios especializados para el mejoramiento de procesos productivos. 
- Instalar talleres, centros de trabajo y demás unidades de producción, así como almacenes, expendios, sucursales y bodegas que faciliten la venta directa de los productos.

- La celebración de toda clase de contratos de comisión mercantil, mediación, distribución, agencia y representación con cualquier empresa, persona moral o persona física, así como con organismos del sector público o privado nacional o extranjero.

- La realización de toda clase de trámites y gestoría ante las agencias aduanales para importaciones y exportaciones.

- Adquirir, vender, dar y recibir en arrendamiento y gravar, toda clase de bienes muebles e inmuebles que se necesiten o relacionen con el objeto de la sociedad.

- Obtener o conceder préstamos otorgando y recibiendo garantías específicas, aceptar, girar, endosar o avalar toda clase de títulos de crédito y otorgar fianzas o garantías de cualquier clase, ya sea para garantizar obligaciones propias o de terceros.

- Obtener, adquirir, explotar, otorgar, transmitir y, en general, disponer por cualquier título de patentes, marcas, nombres comerciales.

- Realizar actos de comercio a que pueda legítimamente acceder en los términos de la ley general de sociedades cooperativas.

- Pedir créditos de capital privado y con organismos gubernamentales y de otras fuentes de financiamiento tanto nacionales como extranjeras, para el desarrollo de las actividades comprendidas en el objeto social.

- Fomentar la realización de actividades de carácter educativo y cultural que apoyen el desarrollo integral del entorno social, extendiendo tales servicios a los grupos, comunidades y organizaciones que lo soliciten.

- Crear las secciones de consumo, vivienda, defunción y conservación ecológica, para proporcionar estos servicios a los socios, además de cuidar y preservar el medio ambiente y los recursos naturales; fomentar el uso de productos biodegradables y reciclables, así como el uso de tecnologías alternativas.

- Crear una sección para la planeación, ejecución, gestión y desarrollo de los proyectos productivos, de comercialización y de servicios.

- Crear las secciones que se consideren necesarias para el cumplimiento del objeto social de la sociedad y, en general, para el mejoramiento de la calidad de vida y nivel cultural de los socios, sus familias y la comunidad. (Ibidem: 8-10). 
Así mismo, los principios bajo los cuales deben supeditar su actuar las sociedades cooperativas son:

Artículo 6. Las sociedades cooperativas deberán observar en su funcionamiento los siguientes principios:

I. Libertad de asociación y retiro voluntario de los socios;

II. Administración democrática;

III. Limitación de intereses a algunas aportaciones de los socios si así se pactara;

IV. Distribución de los rendimientos en proporción a la participación de los socios;

V. Fomento de la educación cooperativa y de la educación en la economía solidaria;

VI. Participación en la integración cooperativa;

VII. Respeto al derecho individual de los socios de pertenecer a cualquier partido político o asociación religiosa, y

VIII. Promoción de la cultura ecológica. (LEY GENERAL DE SOCIEDADES COOPERATIVAS).

\subsection{Constitución, registro y regímenes que puede adoptar una Sociedad Cooperativa}

Respecto a su constitución, registro y regímenes que una sociedad cooperativa puede adoptar, se encuentra fundamentada principalmente en el contenido de los artículos 11 al 16 de la Ley General de Sociedades Cooperativas, mismos que a la letra establecen:

Artículo 11. En la constitución de las sociedades cooperativas se observará lo siguiente:

I. Se reconoce un voto por socio, independientemente de sus aportaciones;

II. Serán de capital variable;

III. Habrá igualdad esencial en derechos y obligaciones de sus socios e igualdad de condiciones para las mujeres;

IV. Tendrán duración indefinida, y

V. Se integrarán con un mínimo de cinco Socios, con excepción de aquellas a que se refiere el Artículo 33 Bis de esta Ley.

Artículo 12. La constitución de las sociedades cooperativas deberá realizarse en asamblea general que celebren los interesados, y en la que se levantara un acta que contendrá:

I. Datos generales de los fundadores; 
II. Nombre de las personas que hayan resultado electas para integrar por primera vez consejos y comisiones, y

III. Las bases constitutivas.

Los socios deberán acreditar su identidad y ratificar su voluntad de constituir la sociedad cooperativa y de ser suyas las firmas o las huellas digitales que obran en el acta constitutiva, ante notario público, corredor público, juez de distrito, juez de primera instancia en la misma materia del fuero común, presidente municipal, secretario, delegado municipal o titular de los órganos político-administrativos del Distrito Federal, del lugar en donde la sociedad cooperativa tenga su domicilio.

Artículo 13. A partir del momento de la firma de su acta constitutiva, las sociedades cooperativas contarán con personalidad jurídica, tendrán patrimonio propio y podrán celebrar actos y contratos, así como asociarse libremente con otras para la consecución de su objeto social.

El acta constitutiva de la sociedad cooperativa de que se trate, se inscribirá en el Registro Público de Comercio que corresponda a su domicilio social.

Artículo 14. Las sociedades cooperativas podrán adoptar el régimen de responsabilidad limitada o suplementada de los socios.

La responsabilidad será limitada, cuando los socios solamente se obliguen al pago de los certificados de aportación que hubieren suscrito. Será suplementada, cuando los socios respondan a prorrata por las operaciones sociales, hasta por la cantidad determinada en el acta constitutiva.

Artículo 15. El régimen de responsabilidad de los socios que se adopte, surtirá efectos a partir de la inscripción del acta constitutiva en el Registro Público de Comercio. Entretanto, todos los socios responderán en forma subsidiaria por las obligaciones sociales que se hubieren generado con anterioridad a dicha inscripción.

Las personas que realicen actos jurídicos como representantes o mandatarios de una sociedad cooperativa no inscrita en el Registro Público de Comercio, responderán del cumplimiento de las obligaciones sociales frente a terceros, subsidiaria, solidaria e ilimitadamente, sin perjuicio de la responsabilidad penal en que hubieren incurrido.

Artículo 16. Las bases constitutivas de las sociedades cooperativas contendrán:

I. Denominación y domicilio social;

II. Objeto social, expresando concretamente cada una de las actividades a desarrollar;

III. Los regímenes de responsabilidad limitada o suplementada de sus socios, debiendo expresar en su denominación el régimen adoptado; 
IV. Forma de constituir o incrementar el capital social, expresión del valor de los certificados de aportación, forma de pago y devolución de su valor, así como la valuación de los bienes y derechos en caso de que se aporten;

V. Requisitos y procedimiento para la admisión, exclusión y separación voluntaria de los socios;

VI. Forma de constituir los fondos sociales, su monto, su objeto y reglas para su aplicación;

VII. Áreas de trabajo que vayan a crearse y reglas para su funcionamiento y en particular de la de educación cooperativa en los términos del artículo 47 de esta Ley;

VIII. Duración del ejercicio social que podrá coincidir con el año de calendario, así como el tipo de libros de actas y de contabilidad a llevarse;

IX. Forma en que deberá caucionar su manejo el personal que tenga fondos y bienes a su cargo;

$X$. El procedimiento para convocar y formalizar las asambleas generales ordinarias que se realizarán por lo menos una vez al año, así como las extraordinarias que se realizarán en cualquier momento a pedimento de la Asamblea General, del Consejo de Administración, del de Vigilancia o del 20\% del total de los miembros;

$\mathrm{XI}$. Derechos y obligaciones de los socios, así como mecanismos de conciliación y arbitraje en caso de conflicto sobre el particular;

XII. Formas de dirección y administración interna, así como sus atribuciones y responsabilidades, y

XIII. Las demás disposiciones necesarias para el buen funcionamiento de la sociedad cooperativa siempre que no se opongan a lo establecido en esta ley.

Las cláusulas de las bases constitutivas que no se apeguen a lo dispuesto por esta ley, serán nulas de pleno derecho para todos los efectos legales correspondientes. (Idem)

\subsection{Clasificación de las Sociedades Cooperativas}

Por lo que toca a la clasificación de las sociedades cooperativas, se encuentra regulado dentro de la Ley General de Sociedades Cooperativas, en su Capítulo II, denominado "De las distintas clases y categorías de sociedades cooperativas», abarcando de los artículos 21 al 33 bis 3 , clasificándolas legalmente en tres: 
Artículo 21. Forman parte del Sistema Cooperativo las siguientes clases de sociedades cooperativas:
I. De consumidores de bienes y/o servicios, y
II. De productores de bienes y/o servicios, y
III. De ahorro y préstamo. (Idem)

Debiendo entender por cada una de ellas, lo siguiente:

A. Sociedades Cooperativas de Consumidores. Son aquéllas cuyos miembros se asocian con el objeto de obtener en común artículos, bienes y/o servicios para ellos, sus hogares o sus actividades de producción; además de que independientemente de la obligación de distribuir artículos o bienes de los socios, podrán realizar operaciones con el público en general siempre que se permita a los consumidores afiliarse a las mismas en el plazo que establezcan sus bases constitutivas, no requiriendo más autorizaciones que las vigentes para la actividad económica específica; de ahí que también las sociedades cooperativas de consumidores puedan dedicarse a actividades de abastecimiento y distribución, así como a la prestación de servicios relacionados con la educación o la obtención de vivienda.

B. Sociedades Cooperativas de Productores. Son aquéllas cuyos miembros se asocien para trabajar en común en la producción de bienes y/o servicios, aportando su trabajo personal, físico o intelectual; además de que independientemente del tipo de producción a la que estén dedicadas estas, de igual forma podrán llevar a cabo actividades encaminadas a almacenar, conservar, transportar y comercializar sus productos. Cabe aclarar que en las sociedades cooperativas de productores cuya complejidad tecnológica lo amerite, deberá haber una Comisión Técnica, integrada por el personal técnico que designe el Consejo de Administración y por un delegado de cada una de las áreas de trabajo en que podrá estar dividida la unidad productora.

A su vez las Sociedades Cooperativas de Productores, pueden hacerse presentes a través de dos categorías: a) Ordinarias. Las que para funcionar requieren únicamente de su constitución legal. b) De participación estatal. Las que se asocien con autoridades federales, estatales, municipales o los órganos político-administrativos del Distrito Federal, para la explotación de unidades productoras o de servicios públicos, dados en administración, o para financiar proyectos de desarrollo económico a 
niveles local, regional o nacional. Para tal efecto, el Estado podrá dar en concesión o administración bienes o servicios a las sociedades cooperativas, en los términos que señalen las leyes respectivas.

C. Sociedades Cooperativas de Ahorro y Préstamo. Estas se regirán por un lado, por la Ley General de Sociedades Cooperativas, así como, por lo dispuesto por la Ley para Regular las Actividades de las Sociedades Cooperativas de Ahorro y Préstamo, debiendo constituirse con un mínimo de veinticinco socios, debiendo entender por el término ahorro, la captación de recursos a través de depósitos de ahorro de dinero de sus socios; y por el vocablo préstamo, la colocación y entrega de los recursos captados entre sus mismos Socios.

La clasificación que antecede queda ilustrada de una mejor manera, a través de la Tesis aislada emitida por el Tercer Tribunal Colegiado en materia Civil del Primer Circuito, misma que a continuación se transcribe:

\section{SOCIEDADES COOPERATIVAS. SU CLASIFICACIÓN.}

Dentro de la clasificación adoptada por la Ley General de Sociedades Cooperativas en sus artículos 22 a 29, encontramos a las cooperativas de consumo y a las de producción. Las primeras se caracterizan porque los socios cooperativistas son los usuarios de los productos que comercializan, los cuales, aunque no son los únicos, se establecen principalmente en relación con la compra de productos de primera necesidad, en virtud de lo cual los socios pueden adquirir productos a mejor precio posible que si los adquirieran por sí mismos. Las segundas comprenden el trabajo común en la realización de actividades en cualquier ámbito de la actividad humana. En ambos casos, la sociedad cooperativa se encuentra dirigida a un sector especial de la sociedad: la clase trabajadora, la cual en muchos de los casos no cuenta con un gran capital que le permita competir o insertarse en actividades económicas propias de las demás sociedades mercantiles, pues es a través de la aportación de su trabajo personal o de la utilización o adquisición de los servicios que la propia cooperativa distribuye que se mantiene la actividad de aquélla. ${ }^{3}$

3 Amparo directo 671/2010. Porfirio Azpeitia Santiago y otros. 12 de mayo de 2011. Unanimidad de votos. Ponente: Benito Alva Zenteno. Secretaria: Sandra Luz Marín Martínez. Semanario Judicial de la Federación. Décima época. Libro XV, Diciembre de 2012, p. 1569. Registro 159890. 


\subsection{Estructura, funcionamiento y administración de las Sociedades Cooperativas}

Referente a la estructura, funcionamiento y administración de las sociedades cooperativas, estas siempre contarán con un órgano supremo de autoridad, encabezado por la Asamblea General; un órgano ejecutivo, comprendido por el Consejo de Administración; un órgano de control o supervisión, recayendo en el Consejo de Vigilancia; y un cuerpo de apoyo, en el cual pueden actuar distintas comisiones creadas y reguladas según las necesidades propias de cada cooperativa.

Lo anterior, queda previsto por el artículo 34 de la Ley General de Sociedades Cooperativas, que textualmente señala:

Artículo 34. La dirección, administración y vigilancia interna de las Sociedades Cooperativas, en general, estará a cargo de los órganos siguientes:

I. La Asamblea General;

II. El Consejo de Administración;

III. El Consejo de Vigilancia;

IV. Las comisiones y comités que esta Ley establece y las demás que designe la Asamblea General, y

V. Tratándose de las Sociedades Cooperativas de Ahorro y Préstamo, además de los citados órganos, en las fracciones I a IV anteriores, deberán contar, cuando menos con:

a) Comité de Crédito o su equivalente;

b) Comité de Riesgos;

c) Un director o gerente general, y

d) Un auditor Interno... (Idem)

\subsection{Régimen Económico de las Sociedades Cooperativas}

En lo tocante a su régimen económico, el capital de las sociedades cooperativas se integra "con las aportaciones de los socios y con los rendimientos que la Asamblea General acuerde se destinen para incrementarlo...» (Idem), además de considerar «la emisión de certificados de aportación para capital de riesgo por tiempo determinado según lo previsto por el artículo 63...» (Idem) de la Ley General de Sociedades Cooperativas.

Tales aportaciones podrán hacerse en efectivo, a través de bienes derechos o trabajo; y estarán representadas por certificados que serán 
nominativos, indivisibles y de igual valor, las cuales deberán actualizarse cada año; además de que dichas participaciones, podrán ser transmitidas como derechos patrimoniales amparados a través de certificados de aportación en favor del beneficiario que designe para el caso de su muerte, de manera que cada socio deberá aportar por lo menos el valor de un certificado, pudiendo pactar la suscripción de certificados excedentes o voluntarios, los cuales percibirán el interés que fije el Consejo de Administración. Sin embargo, al momento de la constitución de una sociedad cooperativa, o al ingresar un nuevo socio, será obligatoria la exhibición del diez por ciento cuando menos del valor de los certificados de aportación.

Para el manejo de los porcentajes que amparan los certificados de aportación, las sociedades cooperativas nacionales pueden constituir tres fondos sociales:

Artículo 53. Las sociedades cooperativas podrán constituir los siguientes fondos sociales:

I. De Reserva;

II. De Previsión Social, y

III. De Educación Cooperativa. (Idem)

A. De conformidad con los artículos 54 y 55 de la Ley General de Sociedades Cooperativas, el fondo de reserva, mismo que se constituirá con una proporción del diez al veinte por ciento de los rendimientos que obtengan las sociedades cooperativas en cada ejercicio social; delimitándose a través de las bases constitutivas, pero sin ser menor del veinte cinco por ciento del capital social en las sociedades cooperativas de productores, ni del diez por ciento en las de consumidores, pudiéndose destinar para afrontar pérdidas o restituir el capital de trabajo, y debiéndose reintegrar al final del ejercicio social, con cargo a los rendimientos.

B. El fondo de previsión social previsto por los artículos 57 y 58 de la misma Ley General de Sociedades Cooperativas, los cuales señalan que: no podrá ser limitado; y deberá destinarse a reservas para cubrir los riesgos y enfermedades profesionales, formar fondos de pensiones y haberes de retiro para los socios, primas de antigüedad, además de cubrir otros conceptos tales como: gastos médicos y de funeral, subsidios por incapacidad, becas educacionales para los socios o sus hijos, guarderías infantiles, actividades culturales y deportivas, así como otras prestaciones de previsión social de naturaleza análoga. 
Siendo necesario aclarar, que las prestaciones derivadas del fondo de previsión social, serán independientes de las prestaciones a que tengan derecho los socios por su afiliación a los sistemas de seguridad social, toda vez que las sociedades cooperativas en general, están obligadas a afiliar a sus trabajadores, y socios que aporten su trabajo personal, a los sistemas de seguridad social, e instrumentar las medidas de seguridad e higiene en el trabajo, así como de capacitación y adiestramiento; además de que dicho fondo deberá constituirse con la aportación anual del porcentaje que sobre los ingresos netos sea determinado por la Asamblea General.

C. Por último, el fondo de educación cooperativa, este se constituirá con el porcentaje que acuerde la Asamblea General, no pudiendo ser inferior al uno por ciento de los excedentes netos del mes.

\subsection{Las Socios de las Sociedades Cooperativas}

Otro aspecto importante para su análisis, comprende a aquellos que forman parte de las sociedades cooperativas en su calidad de socios, mismos que tienen los siguientes derechos y obligaciones:

\section{Derechos}

- Participar con voz y voto en las asambleas.

- Exigir a los órganos de administración y de vigilancia, la presentación de informes periódicos sobre la situación que guarda la sociedad.

- Participar como candidato a ocupar cualquier cargo en los órganos de administración y de vigilancia de la sociedad.

- Especializarse, técnica y administrativamente, al participar en los programas de capacitación, adiestramiento y educación que desarrolle la sociedad.

- Disfrutar de las utilidades que obtenga la sociedad, al término del ciclo productivo o del año fiscal, conforme al \% que acuerde la asamblea.

- Separarse voluntariamente de la sociedad en cualquier tiempo y momento, previo aviso a los órganos internos.

- Presentar iniciativas para el éxito de la sociedad.

- En caso de enfermedad profesional o muerte, designar a quien será el beneficiario de las partes que correspondan por concepto de utilidades $u$ otros beneficios.

- Estímulo a los socios que cumplan cabalmente con sus obligaciones. 
Así también, los siguientes derechos explícitos:

- La obligación de consumir o de utilizar los servicios que las sociedades cooperativas de consumidores brindan a sus socios;

- En las sociedades cooperativas de productores, la prestación del trabajo personal de los socios podrá ser físico, intelectual o de ambos géneros;

- Las sanciones a los socios de las sociedades cooperativas cuando no concurran a las asambleas generales, juntas o reuniones que establece la presente Ley; éstas deberán considerar las responsabilidades y actividades propias de la mujer;

- Las sanciones contra la falta de honestidad de socios y dirigentes en su conducta o en el manejo de fondos que se les hayan encomendado;

- Los estímulos a los socios que cumplan cabalmente con sus obligaciones, y

- La oportunidad de ingreso a las mujeres, en particular a las que tengan bajo su responsabilidad a una familia.

\section{Obligaciones}

- Aportar su trabajo personal para el cumplimiento de los fines de la sociedad.

- Realizar las aportaciones al capital social que se determinen en la asamblea.

- Consumir o utilizar los servicios que las sociedades cooperativas de consumidores brindan a sus socios.

- Asistir con voz y voto a las asambleas que sean convocadas.

- Desempeñar con eficiencia, lealtad y honestidad los cargos y comisiones que la asamblea les confiera.

- Denunciar cualquier anomalía o acto ilícito que ponga en riesgo la integridad de la sociedad.

- Resguardar y mantener en óptimas condiciones el mobiliario y equipo de trabajo que les sean entregados, para el desempeño de sus funciones.

- Informar a los órganos internos, sobre el avance y desviaciones que se den durante la operación de los proyectos y programas de trabajo de la sociedad. (ONG CONTRALORÍA CIUDADANA PARA LA RENDICIÓN DE CUENTAS, A.C., 2009: 29-30).

Así mismo, los artículos 64 y 65 de la Ley General de Sociedades Cooperativas prevén que:

Artículo 64. Esta Ley y las bases constitutivas de cada sociedad cooperativa, determinarán deberes, derechos, aportaciones, causas 
de exclusión de socios y demás requisitos. En todo caso, deberán observarse las siguientes disposiciones:

I. La obligación de consumir o de utilizar los servicios que las sociedades cooperativas de consumidores brindan a sus socios;

II. En las sociedades cooperativas de productores, la prestación del trabajo personal de los socios podrá ser físico, intelectual o de ambos géneros;

III. Las sanciones a los socios de las sociedades cooperativas cuando no concurran a las asambleas generales, juntas o reuniones que establece la presente Ley; éstas deberán considerar las responsabilidades y actividades propias de la mujer;

IV. Las sanciones contra la falta de honestidad de socios y dirigentes en su conducta o en el manejo de fondos que se les hayan encomendado;

V. Los estímulos a los socios que cumplan cabalmente con sus obligaciones, y

VI. La oportunidad de ingreso a las mujeres, en particular a las que tengan bajo su responsabilidad a una familia.

Artículo 65. Las sociedades cooperativas de productores podrán contar con personal asalariado, únicamente en los casos siguientes:

I. Cuando las circunstancias extraordinarias o imprevistas de la producción o los servicios lo exijan;

II. Para la ejecución de obras determinadas;

III. Para trabajos eventuales o por tiempo determinado o indeterminado, distintos a los requeridos por

IV. el objeto social de la sociedad cooperativa;

V. Para la sustitución temporal de un socio hasta por seis meses en un año, y

VI. Por la necesidad de incorporar personal especializado altamente calificado.

... (LEY GENERAL DE SOCIEDADES COOPERATIVAS)

Este último artículo, refiere al personal asalariado del que se pueden allegar las sociedades cooperativas de producción, a través de la celebración de un contrato individual de trabajo, dando paso con ello, a la obligatoriedad de estas de proporcionar tanto a sus trabajadores, como a sus socios, la protección bajo algún esquema de seguridad social, así como de previsión social; que para el caso del Estado mexicano en particular, tales deberes deberán tramitarse y validarse ante el Instituto Mexicano del Seguro Social (IMSS), y el Instituto del Fondo Nacional de Vivienda para los Trabajadores (INFONAVIT). 


\subsection{Disolución, liquidación y fusión de las Sociedades Cooperativas}

Tocando el punto de la disolución y liquidación de las sociedades cooperativas, estas podrán disolverse por cualquiera de las siguientes causales:

I. Por la voluntad de las dos terceras partes de los socios;

II. Por la disminución de socios a menos de cinco;

III. Porque llegue a consumarse su objeto;

IV. Porque el estado económico de la sociedad cooperativa no permita continuar las operaciones, y

V. Por la resolución ejecutoriada dictada por los órganos jurisdiccionales que señala el artículo 9 de esta ley. (Ibidem: Artículo 66).

Debiendo tomar en cuenta que para el caso de llevarse a cabo la liquidación y/o disolución de una sociedad cooperativa, esta deberá ser resuelta por sus órganos de gobierno, en un plazo de diez días hábiles, a fin de decidir sobre la forma de repartición de los fondos de reserva, previsión social y educación aplicables.

Para el caso de fusionarse dos o más sociedades cooperativas, «... la sociedad fusionante que resulte de la fusión, tomará a su cargo los derechos y obligaciones de las fusionadas», debiendo «... seguir el mismo trámite que la Ley General de Sociedades Cooperativas establece para su constitución». (Ibidem: Artículos 72-73).

\subsection{Régimen Fiscal de las Sociedades Cooperativas}

Finalmente, el régimen fiscal aplicable a las sociedades cooperativas corresponde al régimen general, para lo cual deberá tomar en cuenta las siguientes bases generales y de tramitología:

\section{Tramitología}

1. Obtiene permiso de la Secretaria de Relaciones Exteriores para su constitución.

2. Realiza la formulación de sus bases constitutivas.

3. Registro ante fedatario público, notario, corredor público, presidente municipal, funcionario habitado (obtiene sello).

4. Concurre a inscribir en el registro público de la propiedad y el comercio.

5. Registra ante la Secretaria de Hacienda y Crédito Público. 
Generales

1. La sociedad cooperativa es causante de Impuesto Sobre la Renta (ISR).

2. Retenedor del Impuesto al Valor Agregado (IVA) ya que otorga facturas.

3. Se le asignan las siglas S.C. DE R.L. DE C.V., O S.C. DE R.S. DE C.V., según el caso.

4. Obtendrá su Registro Federal de Contribuyentes (RFC).

5. Debe contar con una cuenta bancaria mancomunada.

6. Debe dar aviso de su apertura y solicitara el certificado de zonificación, para lo que deberá acudir a protección civil, de ser necesario obtendrá licencia sanitaria del sector salud, Instituto

7. Mexicano del Seguro Social (IMSS), al sistema de información empresarial mexicano (SIEM), a la secretaría del trabajo y previsión social (STPS). Se registrara en el instituto nacional de geografía y estadística (INEGI), en la Secretaria de Economía (SE) y en su caso en la Secretaria del Medio Ambiente. (ONG CONTRALORÍA CIUDADANA PARA LA RENDICIÓN DE CUENTAS, A.C., 2009: 41).

\section{Las Sociedades Cooperativas y su obligatoriedad ante el Instituto Mexicano del Seguro Social (IMSS)}

Referir a la obligación que tienen las sociedades cooperativas tanto en su carácter de socio cooperativista, como de empleador, conlleva a determinar el deber de estas, primeramente, de inscribirse y registrase ante el Instituto Mexicano del Seguro Social (IMSS), constituyéndose ésta última como un esquema especializado de seguridad social, bajo el cual los socios de las cooperativas y el personal contratado por estas puedan accesar a prestaciones y servicios de salud, además de prestaciones económicas como subsidios, pensiones e indemnizaciones, ambas prestaciones tanto económicas como en especie derivadas de los seguros que la Ley del Seguro Social en su artículo 11 contempla; en segundo término de la obligación de afiliar a sus trabajadores ante el IMSS y el Instituto del Fondo Nacional de la Vivienda para los Trabajadores (INFONAVIT); en tercer lugar, el compromiso de cubrir de manera oportuna sus cuotas obrero patronales ante ambas instituciones, de conformidad con el salario base de cotización que las leyes sobre la materia les fijen, así como de todos aquellos demás deberes inherentes e ineludibles señalados por el artículo 15 de la Ley del Seguro Social.

Por ello, en este apartado se analizarán los sujetos de aseguramiento de las sociedades cooperativas, el régimen bajo el cual cotiza- 
ran estas, así como la forma de integración del salario base de cotización tanto para los socios cooperativistas, como para los trabajadores de las cooperativas; el requisito de inscripción y/o registro, y de pago de las aportaciones que deben cubrir estas ante el Instituto Mexicano del Seguro Social (IMSS) y el Instituto del Fondo Nacional de la Vivienda para los Trabajadores (INFONAVIT).

\subsection{Sujetos de aseguramiento ante el IMSS}

La obligatoriedad de las sociedades cooperativas de afiliar a sus trabajadores y a sus socios bajo algún esquema de seguridad social nacional, lo mandata en primer término el párrafo último del artículo 57 de la Ley General de Sociedades Cooperativas, al prever que: «... Las sociedades cooperativas en general, deberán de afiliar obligatoriamente a sus trabajadores, y socios que aporten su trabajo personal, a los sistemas de seguridad social, e instrumentar las medidas de seguridad e higiene en el trabajo, así como de capacitación y adiestramiento, gozando del beneficio expresado en los artículos 116 y 179 de la Ley del Seguro Social». (LEY GENERAL DE SOCIEDADES COOPERATIVAS).

Del contenido de este artículo, se desprende la necesidad de analizar primeramente, el artículo 12 de la Ley del Seguro Social, pues en él se establecen los sujetos que de manera imperativa deben ser objeto de incorporación obligatoria ante el Instituto Mexicano del Seguro Social (IMSS), recordando que esta Ley regula en su artículo $6 .^{\circ}$ dos vías para acceder a los servicios y prestaciones que el propio instituto establece: el régimen obligatorio y el régimen voluntario.

El primero, comprende la afiliación forzosa de los trabajadores al momento de ser sujetos de una relación laboral formalizada o no a través de un contrato individual de trabajo; y el segundo, refiere a la incorporación voluntaria de un trabajador, dividiéndose a su vez en: la continuación voluntaria, la cual implica que el trabajador ha dejado de ser sujeto de una contratación laboral por dejar de prestar sus servicios a un patrón y al cubrir por lo menos «un mínimo de cincuenta y dos cotizaciones semanales acreditadas en el régimen obligatorio, en los últimos cinco años, al ser dado de baja, tiene el derecho a continuar voluntariamente en el mismo, pudiendo continuar en los seguros conjuntos de invalidez y vida, así como, de retiro, cesantía en edad avanzada y vejez, debiendo quedar inscrito con el último salario o superior al que tenía en el momento de la baja». (LEY DE SEGURO SOCIAL: Artículo 218). Así como, la incorporación voluntaria de los 
sujetos a que alude el artículo 13 de la misma Ley del Seguro Social, la cual se:

... realizará por convenio y se sujetará a las siguientes modalidades:

I. Podrá efectuarse en forma individual o de grupo a solicitud, por escrito, del sujeto o sujetos interesados. En el caso de incorporación colectiva cada uno de los asegurados será responsable de sus obligaciones frente al Instituto;

II. El esquema de aseguramiento, para los sujetos que señala este capítulo, comprende:

a) Para los sujetos a que se refieren las fracciones I y III del artículo 13 de esta Ley, las prestaciones en especie del seguro de enfermedades y maternidad y las correspondientes de los seguros de invalidez y vida, así como de retiro y vejez, en los términos de los capítulos respectivos;

b) Para los sujetos a que se refiere la fracción II del artículo 13 de esta Ley, las prestaciones en especie de los seguros de riesgos de trabajo y de enfermedades y maternidad y las correspondientes de los seguros de invalidez y vida, así como de retiro, cesantía en edad avanzada y vejez, en los términos de los capítulos respectivos;

c) Para los sujetos a que se refiere la fracción IV del artículo 13 de esta Ley, las prestaciones del seguro de riesgos de trabajo, las prestaciones en especie del seguro de enfermedades y maternidad y las correspondientes de los seguros de invalidez y vida, así como de retiro y vejez, en los términos de los capítulos respectivos;

d) Para los sujetos a que se refiere la fracción $\vee$ del artículo 13 de esta Ley, las prestaciones del seguro de riesgos de trabajo, las prestaciones en especie del seguro de enfermedades y maternidad y las correspondientes de los seguros de invalidez y vida, así como de retiro, cesantía en edad avanzada y vejez, en los términos de los capítulos respectivos, y

A solicitud de las entidades públicas, el esquema de aseguramiento podrá comprender únicamente las prestaciones en especie de los seguros conjuntos de riesgos de trabajo y enfermedades y maternidad, siempre y cuando dichas entidades tengan establecido un sistema de pensiones para sus trabajadores, y

e) En caso de muerte del asegurado, se estará a lo dispuesto en el artículo 104 de esta Ley. (Ibidem: Artículo 222). 
De manera que el artículo 12 de la Ley del Seguro Social indica que:

Son sujetos de aseguramiento del régimen obligatorio:

I. Las personas que de conformidad con los artículos 20 y 21 de la Ley Federal del Trabajo, presten, en forma permanente o eventual, a otras de carácter físico o moral o unidades económicas sin personalidad jurídica, un servicio remunerado, personal y subordinado, cualquiera que sea el acto que le dé origen y cualquiera que sea la personalidad jurídica o la naturaleza económica del patrón aun cuando éste, en virtud de alguna ley especial, esté exento del pago de contribuciones;

II. Los socios de sociedades cooperativas, y

III. Las personas que determine el Ejecutivo Federal a través del Decreto respectivo, bajo los términos y condiciones que señala esta Ley y los reglamentos correspondientes. (Idem)

Bajo esa línea, es entendible que el propio artículo 12 en comento, precisa en su fracción II a los socios de sociedades cooperativas como sujetos de incorporación obligatoria, sin embargo, en ningún momento hace mención de aquellos sujetos que presten sus servicios como trabajadores a una sociedad cooperativa, para lo cual es preciso recordar:

que únicamente la legislación había considerado — sólo— a los socios de cooperativas de producción como sujetos de afiliación obligatoria del seguro social, pero - a través de la reforma hecha a la Ley sobre la materia publicada mediante Decreto del veintiuno de diciembre de dos mil uno- se incluyen - también- a los miembros de cooperativas de consumo en las mismas características que los anteriores, no obstante que los fines de estas últimas sean de proteger los intereses comunes de los agremiados, pero se pensó que también son económicamente débiles y por esa razón se adicionaron en el esquema obligatorio, todo ello con base en el artículo 57 de la Ley de Sociedades Cooperativas que enuncia que cualquier clase de estas sociedades debe incorporar a sus socios a la seguridad social. (MORENO, 2010: 22-23).

Aunque también «el artículo 19 de la Ley —del Seguro Socialmenciona que los socios se equiparan a los trabajadores y la cooperativa a los patrones, teniendo como base de pago, la que se desprende del artículo 51 del reglamento de la Ley en la materia». (Ibidem: 23) ${ }^{4}$.

${ }^{4}$ Cfr. Artículo 19 de la Ley del Seguro Social. Para los efectos de esta Ley, las sociedades cooperativas pagarán la cuota correspondiente a los patrones, y cada uno de los socios a que se refiere la fracción II del artículo 12 de esta Ley cubrirán sus cuotas como trabajadores. (LEY DE SEGURO SOCIAL). 
Lo anterior, permite entender que si bien «las sociedades cooperativas son constituidas por personas físicas cuyo interés en común es satisfacer sus necesidades propias y —las de la - comunidad mediante la realización de actividades económicas de producción, distribución y consumo de bienes y servicios, todo esto con su esfuerzo propio y la ayuda mutua de sus integrantes, y bajo los principios de solidaridad» (PÉREZ y Fol, 2012: 405), estas se pueden encontrar integradas tanto por sus socios que laboran en beneficio propio y de la cooperativa «al crear para sí puestos de trabajo» (Idem), "como de trabajadores que prestan sus servicios a esta, toda vez que la mismas cooperativas, - - sobre todo las de producción - se encuentran habilitadas para contratar personal a su cargo». (Idem).

Es decir, que los socios de las cooperativas no prestan sus servicios como consecuencia de un contrato o relación de trabajo con la sociedad, sino más bien es una obligación propia de su calidad de socios cooperativistas, sobre todo por cuanto hace a las sociedades cooperativas de producción, pues como lo disponen los artículos 27 y 64 de la Ley General de Sociedades Cooperativas, deben apoyar con su trabajo personal para lograr el objetivo de la sociedad. ${ }^{5}$

Ello se debe a que antes de la reforma al artículo 19 de la Ley del Seguro Social vigente durante 1995-1997, el régimen de cotización que prevalecía entre las sociedades cooperativas contemplaba únicamente a las cooperativas de producción a través de una cotización bipartita y excluía a las cooperativas de consumo, pero al operar la reforma al mencionado artículo el veintiuno de diciembre de dos mil uno,

Artículo 51 del Reglamento de la Ley del Seguro Social en Materia de Afiliación, Clasificación de Empresas, Recaudación y Fiscalización. Para efectos de la determinación de las percepciones base de cotización de los socios de las sociedades cooperativas, se aplicarán las reglas previstas en la fracción II del artículo 30 de la Ley.

5 Artículo 27 de la Ley General de Sociedades Cooperativas. Son sociedades cooperativas de productores, aquéllas cuyos miembros se asocien para trabajar en común en la producción de bienes y/o servicios, aportando su trabajo personal, físico o intelectual. Independientemente del tipo de producción a la que estén dedicadas, estas sociedades podrán almacenar, conservar, transportar y comercializar sus productos, actuando en los términos de esta Ley.

Artículo 64 Ley General de Sociedades Cooperativas. Esta Ley y las bases constitutivas de cada sociedad cooperativa, determinarán deberes, derechos, aportaciones, causas de exclusión de socios y demás requisitos. En todo caso, deberán observarse las siguientes disposiciones:

II. En las sociedades cooperativas de productores, la prestación del trabajo personal de los socios podrá ser físico, intelectual o de ambos géneros; 
«ahora se reputan como patrones a todas las cooperativas, del tipo que sean. Además de establecer, que cada uno de los socios deben cubrir sus cuotas como cualquier trabajador al servicio de un patrón» (ALCARÁZ, 2009: 31), aspecto que dio cabida a un régimen de cotización tripartita.

Tal aspecto, se puede confirmar a través de la tesis expuesta por el Tercer Tribunal Colegiado del Segundo Circuito, la cual de manera textual dice:

\section{COOPERATIVA DE PRODUCCIÓN, SUS SOCIOS NO DEBEN SER CONSIDERADOS TRABAJADORES DE LA MISMA.}

Si la sociedad cooperativa acredita que el demandante tienen la calidad de socio de la misma, éste no puede alegar que además tenga el carácter de trabajador, en virtud de que de acuerdo con lo que dispone el artículo 56 de la Ley General de Sociedades Cooperativas, los socios deben contribuir con su trabajo para lograr el objetivo de la sociedad; es decir, que el servicio que le prestan sus socios no es como consecuencia de una relación laboral sino como resultado de la obligación inherente a su calidad de socios cooperativistas. Por tanto, debe concluirse que no se dan los supuestos del artículo 20 de la Ley Federal del Trabajo para que puedan ser considerados como trabajadores de la cooperativa. ${ }^{6}$

Sin embargo, el artículo 65 de la misma Ley General de Sociedades Cooperativas prevé que:

Las sociedades cooperativas de productores podrán contar con personal asalariado, únicamente en los casos siguientes:

I. Cuando las circunstancias extraordinarias o imprevistas de la producción o los servicios lo exijan;

II. Para la ejecución de obras determinadas;

III. Para trabajos eventuales o por tiempo determinado o indeterminado, distintos a los requeridos por el objeto social de la sociedad cooperativa;

IV. Para la sustitución temporal de un socio hasta por seis meses en un año, y

V. Por la necesidad de incorporar personal especializado altamente calificado. (Idem).

6 Semanario Judicial de la Federación. Octava época. Tomo X. noviembre 1992. p. 245. Revisión fiscal 20/92. Delegación estatal en Hidalgo del Instituto Mexicano del Seguro Social (IMSS). 20 de agosto de 1992. Unanimidad de votos. 
De manera que, toda sociedad cooperativa tiene la obligación inexcusable de asegurar bajo algún esquema de seguridad social: primeramente, a sus socios, por ser estos quienes integran a la misma, y de forma secundaria, a aquellos sujetos que hubiesen sido contratados por la cooperativa para prestar un trabajo personal subordinado en términos de lo que establecen los artículos 20 y 21 de la Ley Federal del Trabajo, teniendo la calidad de trabajador que el propio artículo $8 .^{\circ}$ de la misma legislación laboral en comento señala, numerales que en su contenido prevén:

Artículo $8^{\circ}$ Trabajador es la persona física que presta a otra, física o moral, un trabajo personal subordinado...

Artículo 20. Se entiende por relación de trabajo, cualquiera que sea el acto que le dé origen, la prestación de un trabajo personal subordinado a una persona, mediante el pago de un salario.

Contrato individual de trabajo, cualquiera que sea su forma o denominación, es aquel por virtud del cual una persona se obliga a prestar a otra un trabajo personal subordinado, mediante el pago de un salario.

La prestación de un trabajo a que se refiere el párrafo primero y el contrato celebrado producen los mismos efectos.

Artículo 21. Se presumen la existencia del contrato y de la relación de trabajo entre el que presta un trabajo personal y el que lo recibe. (LEY FEDERAL DEL TRABAJO).

\subsection{Inscripción Patronal de las Sociedades Cooperativas ante el IMSS}

De acuerdo a lo establecido por el artículo 19 de la Ley del Seguro Social, cada una de las sociedades cooperativas están obligadas a enterar la cuota correspondiente a los patrones, y cada uno de los socios deben cubrir el porcentaje relativo en carácter de trabajador, tal como lo refieren las fracciones I y II, del artículo 12 de la misma ley, el cual establece:

Son sujetos de aseguramiento del régimen obligatorio:

I. Las personas que de conformidad con los artículos 20 y 21 de la Ley Federal del Trabajo, presten, en forma permanente o eventual, a otras de carácter físico o moral o unidades sin personalidad jurídica un servicio remunerado, personal y subordinado, cualquiera que sea el acto que le dé origen y cualquiera que sea la personalidad jurídica o la naturaleza económica del patrón aun cuando éste, en virtud de alguna ley especial, esté exento del pago de contribuciones; 
II. Los socios de sociedades cooperativas... (LEY DEL SEGURO $\mathrm{SOCIAL)}$.

Así mismo, el artículo 15 de la Ley del Seguro Social indica que:

Los patrones están obligados a:

I. Registrarse e inscribir a sus trabajadores en el Instituto, comunicar sus altas y bajas, las modificaciones de su salario y los demás datos, dentro de plazos no mayores de cinco días hábiles; (Idem).

De lo anterior, es deducible que la obligación de cualquier persona física o moral de registrarse como patrón o sujeto obligado ante el IMSS, se inicia a partir del momento en que se da comienzo a la relación laboral, al constituirse la sociedad cooperativa, o bien, al iniciar la vigencia del convenio celebrado, o del Decreto respectivo. ${ }^{7}$

\subsection{Registro patronal para el caso de las Sociedades Cooperativas}

Derivado de las obligaciones patronales contenidas en los artículos 12 y 15 de la Ley del Seguro Social, y 57 de la Ley General de Sociedades Cooperativas, cuando estas agrupaciones actúen en su calidad de patronos o empleadores, deberán dar cumplimiento a tales deberes, para lo cual, tratándose de los socios, tendrán que tramitar su registro patronal ante el Instituto Mexicano del Seguro Social (IMSS), además de llevar a cabo el aseguramiento de sus trabajadores, lo cual indica que las cooperativas tienen la obligación de llevar a cabo un doble y especial registro patronal: por un lado el de sus socios, mismos que tendrán el carácter de empleador; y por otro, el de su personal contratado, tal como se prevé en el contenido del párrafo último, del artículo 13 del Reglamento de la Ley del Seguro Social en

7 Dicha obligación deriva de lo previsto en el artículo 12 del Reglamento de la Ley del Seguro Social en materia de Afiliación, Clasificación de Empresas, Recaudación y Fiscalización, mismo que de forma literal señala: «Cualquier persona física o moral estará obligada a registrarse como patrón o sujeto obligado ante el Instituto a partir de que: I. Empiece a utilizar los servicios de uno o varios trabajadores; II. Se constituya como sociedad cooperativa; III. Inicie vigencia su convenio de incorporación celebrado con el Instituto; y IV. Inicie vigencia el Decreto de incorporación que expida el Ejecutivo Federal en términos de la fracción III del artículo 12 de esta Ley». 
materia de Afiliación, Clasificación de Empresas, Recaudación y Fiscalización. ${ }^{8}$

El trámite de registro y/o inscripción patronal tiene que ser gestionado a través del representante legal de la sociedad cooperativa, quien deberá acreditar su personalidad jurídica mediante poder notarial debidamente fedatado ante Notario Público, en el que se contengan el otorgamiento de facultades "para realizar trámites ante entidades públicas, respecto actos de administración o para pleitos y cobranzas, a nombre del patrón o sujeto obligado». (PÉREZ y Fol, 2012: 405).

Respecto de los documentos que las sociedades cooperativas deben presentar para iniciar su trámite de registro patronal ante el Instituto Mexicano del Seguro Social requieren:

1. En primer término, el Registro Federal de Contribuyentes (RFC), debidamente expedido por la autoridad tributaria correspondiente, siendo esta a través del Servicio de Administración Tributaria de la entidad donde se encuentre ubicado el centro de trabajo, dependencia que se constituye como un organismo público descentralizado de la Secretaría de Hacienda y Crédito Público.

2. En segunda instancia, cualquier comprobante de domicilio del centro de trabajo, mismo que servirá al patrón o sujeto obligado para acreditar el domicilio fiscal, sirviendo como documento probatorio: contratos vigentes y con una antigüedad no mayor a dos meses a nombre de la sociedad cooperativa ${ }^{9}$, estados de cuenta a nombre de la cooperativa con una temporalidad no mayor a los dos meses, recibos a nombre de la sociedad o de un tercero no mayor a cuatro meses, carta de radicación o de residencia a nombre de la sociedad cooperativa de un tiempo no mayor a cuatro meses, comprobante de alineación y número oficial a nombre de la sociedad cooperativa o de un tercero de una antigüedad no mayor a cuatro meses.

3. Un croquis de ubicación del domicilio de trabajo.

8 El artículo 13 del Reglamento de la Ley del Seguro Social en materia de Afiliación, Clasificación de Empresas, Recaudación y Fiscalización, establece las normas a aplicar en la asignación del registro patronal, y a la letra señala: «... En el caso de las sociedades cooperativas, se aplicará un registro patronal para el aseguramiento de sus trabajadores y otro diferente para el aseguramiento de sus socios».

9 El contrato de arrendamiento y/o de subarrendamiento, acompañado del último recibo de pago de la renta que cumpla con los requisitos fiscales, el fideicomiso debidamente protocolizado, la apertura de cuenta bancaria, los recibos de servicios de luz, teléfono y agua; todos estos documentos pueden ser utilizados como contratos vigentes que sirvan para señalar el domicilio del centro de trabajo de la sociedad cooperativa. 
4. La escritura pública o acta constitutiva en la que se contengan los sellos del Registro Público de la Propiedad y del Comercio.

5. Así mismo, el poder notarial en el que se otorguen las facultades de actos de administración del representante legal.

6. Una identificación oficial del representante legal. ${ }^{10}$

7. El Registro Federal de Contribuyentes (RFC) del representante legal.

8. Así como, la Clave Única del Registro de Población (CURP) del representante legal, documento que sirve como una cédula de identidad personal y que es expedido por el Registro Nacional de Población (RENAPO).

Para dar inicio al trámite de inscripción o registro patronal, el representante legal podrá accesar al portal de internet del Instituto Mexicano del Seguro Social (IMSS) ${ }^{11}$, a fin de requisitar todos los datos para la inscripción, además de concertar una cita para acudir a la subdelegación o unidad administrativa del IMSS que le corresponda en razón al domicilio del centro trabajo, lo anterior, con el objeto de entregar la documentación exigida para el trámite, y ya referida en el párrafo que antecede, información que deberá ir acompañada de los formatos ARP$\mathrm{PM}^{12}$ y AFIL-02 ${ }^{13}$ debidamente llenados por la sociedad cooperativa.

Una vez concluido el trámite de inscripción patronal, el representante legal de la sociedad cooperativa, recibirá dentro de un término de setenta y dos horas siguientes, copias de los formatos indicados debidamente sellados, así como de la tarjeta de identificación patronal.

\subsection{El Salario Base de Cotización de las Sociedades Cooperativas}

El artículo 27 de la Ley del Seguro Social, indica que «el Salario Base de Cotización se integra con los pagos hechos en efectivo por cuota diaria, gratificaciones, percepciones, alimentación, habitación, primas, comisio-

10 Pudiendo presentar como tal: credencial para votar con fotografía expedida por el Instituto Federal Electoral (IFE), pasaporte vigente, cartilla de servicio militar, cédula profesional, matricula consular, tarjeta/cédula o carnet para extranjeros, en caso de ser extranjero la forma migratoria FM2 o FM3 debidamente expedida por el Instituto Nacional de Migración (INM).

11 La página web del Instituto Mexicano del Seguro Social es: http://www.imss.gob.mx.

12 El formato ARP-PM «Aviso de Registro Patronal de Personas Morales en el Régimen Obligatorio», fue publicado en el Diario Oficial de la Federación el 17 de marzo de 2010.

13 El formato AFIL-02 «Aviso de Inscripción de los Trabajadores», debe ser presentado en original y dos copias simples. 
nes, prestaciones en especie, y cualquier otra cantidad o prestación que se entregue al trabajador por su trabajo...» (LEY DEL SEGURO SOCIAL).

Sin embargo, de manera específica el artículo 28-A de la Ley del Seguro Social, regula el Salario Base de Cotización para el caso de las sociedades cooperativas, señalando que: «la base de cotización para los sujetos obligados señalados en la fracción II del artículo 12 de esta Ley, se integrará por el total de las percepciones que reciban por la aportación de su trabajo personal, aplicándose en lo conducente lo establecido en los artículos 28, 29, 30, 32 y demás aplicables de esta Ley». (Idem).

En ese sentido, el artículo 28 de la Ley General de Sociedades Cooperativas establece que: "los rendimientos anuales que reporten los balances de las sociedades cooperativas de productores, se repartirán de acuerdo con el trabajo aportado por cada socio durante el año, tomando en cuenta que el trabajo puede evaluarse a partir de los siguientes factores: calidad, tiempo, nivel técnico y escolar». (LEY GENERAL DE SOCIEDADES COOPERATIVAS).

Aunque tal precepto legal, resulta limitativo en cuanto su aplicación para el caso de las sociedades cooperativas de consumo, toda vez que el artículo 24 de la Ley General de Sociedades Cooperativas señala que "los excedentes en las sociedades cooperativas de consumidores que reporten los balances anuales, se distribuirán en razón de las adquisiciones que los socios hubiesen efectuado durante el año fiscal». (Idem).

Sin embargo, con la reforma de diciembre de dos mil uno, el dispositivo del artículo 28-A se incorporó a la Ley del Seguro Social, extendiéndose y beneficiando en su aplicabilidad a las cooperativas de consumo, ya que hasta antes de dicha reforma era imposible aplicar el supuesto del artículo en comento, ya que los ingresos de las cooperativas de consumo no estaban en función del trabajo aportado, sino de acuerdo con las adquisiciones que estas hayan realizado, a diferencia de las cooperativas de producción donde los rendimientos generados por estas son repartidos entre sus socios en razón al trabajo aportado por cada uno de ellos; permitiendo con ello, que las sociedades cooperativas sean de la naturaleza que sea, tengan la obligación de cotizar como cualquier trabajador, aspecto que tuvo como «... finalidad, que las aportaciones de los miembros de las sociedades cooperativas, incluyan además de las retribuciones normales por su trabajo, los rendimientos de las referidas agrupaciones». (MORENO, 2010: 40).

De igual forma el artículo 51 del Reglamento de la Ley del Seguro Social en materia de Afiliación, Clasificación de Empresas, Recaudación y Fiscalización, estima que "para efectos de las percepciones base de cotización de los socios de las sociedades cooperativas, se aplicarán las reglas previstas en la fracción II del artículo 30 de la Ley del Seguro Social». 
(REGLAMENTO DE LA LEY DEL SEGURO SOCIAL EN MATERIA DE AFILIACIÓN, CLASIFICACIÓN DE EMPRESAS, RECAUDACIÓN Y FISCALIZACIÓN).

Por lo que resultan también aplicables a la base de cotización de las sociedades cooperativas los numerales 28, 29, 30 y 32 de la Ley del Seguro Social, los cuales establecen:

Artículo 28. Los asegurados se inscribirán con el salario base de cotización que perciban en el momento de su afiliación, estableciéndose como límite superior el equivalente a veinticinco veces el salario mínimo general que rija en el Distrito Federal y como límite inferior el salario mínimo general del área geográfica respectiva.

Artículo 29. Para determinar la forma de cotización se aplicarán las siguientes reglas:

I. El mes natural será el período de pago de cuotas;

II. Para fijar el salario diario en caso de que se pague por semana, quincena o mes, se dividirá la remuneración correspondiente entre siete, quince o treinta respectivamente. Análogo procedimiento será empleado cuando el salario se fije por períodos distintos a los señalados, y

III. Si por la naturaleza o peculiaridades de las labores, el salario no se estipula por semana o por mes, sino por día trabajado y comprende menos días de los de una semana o el asegurado labora jornadas reducidas y su salario se determina por unidad de tiempo, en ningún caso se recibirán cuotas con base en un salario inferior al mínimo.

Artículo 30. Para determinar el salario diario base de cotización se estará a lo siguiente:

I. Cuando además de los elementos fijos del salario el trabajador percibiera regularmente otras retribuciones periódicas de cuantía previamente conocida, éstas se sumarán a dichos elementos fijos;

II. Si por la naturaleza del trabajo, el salario se integra con elementos variables que no puedan ser previamente conocidos, se sumarán los ingresos totales percibidos durante los dos meses inmediatos anteriores y se dividirán entre el número de días de salario devengado en ese período. Si se trata de un trabajador de nuevo ingreso, se tomará el salario probable que le corresponda en dicho período, y

III. Tratándose de ausencias amparadas por incapacidades médicas expedidas por el Instituto no será obligatorio cubrir las cuotas obrero patronales, excepto por lo que se refiere al ramo de retiro. 
Artículo 32. Si además del salario en dinero el trabajador recibe del patrón, sin costo para aquél, habitación o alimentación, se estimará aumentado su salario en un veinticinco por ciento y si recibe ambas prestaciones se aumentará en un cincuenta por ciento.

Cuando la alimentación no cubra los tres alimentos, sino uno o dos de éstos, por cada uno de ellos se adicionará el salario en un ocho punto treinta y tres por ciento. (LEY DEL SEGURO SOCIAL).

Finalmente, es conveniente acotar en este apartado, que hasta antes de la reforma a la Ley del Seguro Social de 1997, las sociedades cooperativas, sobre todo las de producción, venían realizando sus aportaciones de manera bipartita (gobierno federal y sociedad cooperativa), según lo disponía el artículo tercero transitorio del Decreto de la Ley del Seguro Social, publicado en el Diario Oficial de la Federación el veintiuno de diciembre de mil novecientos noventa y cinco. ${ }^{14}$

Situación que fue modificada a partir del primero de julio de mil novecientos noventa y siete, pues el régimen de cotización de las sociedades cooperativas de producción paso a ser de manera tripartita, debiendo actualmente aportar: los socios cooperativistas, la sociedad cooperativa considerada como patrón y el gobierno federal, lo anterior se vio reforzado con la publicación del Decreto de fecha veinte de diciembre de dos mil uno. ${ }^{15}$

Tal aspecto, puede confirmarse a través de la tesis aislada pronunciada por el Tercer Tribunal Colegiado en materia Administrativa del Primer Circuito, que a la letra establece:

\section{SEGURO SOCIAL. LAS SOCIEDADES COOPERATIVAS QUE CON- TRATAN TRABAJADORES DEBEN COTIZAR BAJO EL REGIMEN TRIPARTITA ALCUBRIR LAS PRIMAS CORRESPONDIENTES Y NO BAJO EL REGIMEN DE EXCEPCION.}

La Ley del Seguro Social prevé dos formas de integrar las cuotas correspondientes a las primas establecidas en ella; por regla general, tales cuotas se integran con la participación económica de los patrones, trabajadores y el Estado, y se les conoce como tripartitas. Como caso de excepción la propia ley reconoce las cuotas bipartitas, que se integran

14 A través del Decreto publicado en el Diario Oficial de la Federación en fecha 20 de diciembre de 2001, se modificó el contenido del artículo 19 de la Ley del Seguro Social, permitiendo y obligando no sólo a las cooperativas de producción, sino también a las de consumo a formar parte de un régimen de cotización tripartita (socios cooperativistas, sociedad cooperativa y el gobierno federal).

15 El Decreto referido puede consultarse en la página web del Diario Oficial de la Federación http://www.dof.gob.mx, accesando al menú de «Búsqueda de la Información-Acceso a búsqueda avanzada». 
con la participación del Estado y los patrones, esa cuota constituye un caso especial para garantizar los beneficios de la seguridad social y se cubren en las situaciones particulares que el propio ordenamiento contempla. Pues bien, la Ley del Seguro Social en sus artículos 116 y 179 establece el régimen de excepción en tratándose de las sociedades cooperativas de producción, con la finalidad de que sus miembros disfruten de la seguridad social, y dispone que tales sociedades cubrirán el cincuenta por ciento de las primas totales y que el gobierno federal cubrirá el otro cincuenta por ciento. La aplicación de esta disposición tiene como presupuesto indispensable el que se trate de los socios de la cooperativa, en quienes se reúne la característica de ser patrones y trabajadores de tal sociedad. En efecto, la sociedad cooperativa es una sociedad clasista, una asociación de individuos de clase trabajadora, animados por las ideas de ayuda mutua y equidad, que mediante la eliminación del intermediarismo, buscan, sin afán de lucro, obtener y repartir directamente y prorrata, entre los socios, beneficios extracapitalistas. Por regla general estas sociedades no pueden contratar trabajadores, así lo dice su ley expresamente, y su base descansa en el trabajo mutuo de sus integrantes; por ello, resulta obvio que el régimen bajo el cual coticen sea el bipartita de excepción, pues al reunirse en los socios la calidad de patrón y trabajador, es claro que no existe la relación tripartita y sería injusto que por un solo sujeto se cobrara una doble contribución. Sin embargo, cuando las sociedades cooperativas contratan trabajadores, se presenta una situación distinta y el régimen de cotización debe ser el tripartita, ya que en este caso, la sociedad, por la naturaleza del vínculo de sus trabajadores, se convierte en un patrón, y debe ser sujeta, como todos los patrones, al régimen obligatorio en los términos de la fracción I del artículo 12 de la Ley del Seguro Social; este precepto establece que las personas vinculadas a otras por una relación de trabajo son sujetos de aseguramiento del régimen obligatorio y mientras no sean considerados como socios de la cooperativa deben cotizar en las mismas condiciones en que lo hace cualquier otro patrón; es decir, bajo el régimen tripartita; pues existiendo la relación trabajador-patrón-Estado, no existe ninguna circunstancia especial para que en este supuesto no se cotice bajo el régimen general como lo hace cualquier otro patrón; considerando, además que esta situación no es la que debe regir en una sociedad cooperativa, que por regla general no puede contratar trabajadores y debe desempeñarse únicamente con el servicio que presten sus socios. ${ }^{16}$

16 Amparo directo 1153/91. Sociedad Cooperativa Manufacturera de Cemento Portland la Cruz Azul, S. C. L. 19 de septiembre de 1991. Unanimidad de votos. Ponente: Genaro David Góngora Pimentel. Secretaria: Guadalupe Margarita Ortiz Blanco. Tercer Tribunal Colegiado en materia Administrativa del Primer Circuito. Semanario Judicial de la Federación. Octava época. Regist5ro 221185. Consultable en: http://www.scjn.gob.mx o de manera directa en: http://200.38.163.178/SJFSem/Paginas/Semanariolndex.aspx 


\subsection{Las Sociedades Cooperativas y sus aportaciones al Instituto del Fondo Nacional de la Vivienda para los Trabajadores (INFONAVIT)}

El derecho de habitación para los trabajadores, se ha constituido en el Estado mexicano, como un derecho de previsión social de carácter prestacional, el cual deriva de la fracción XII, del apartado A) del artículo 123 de la Constitución Federal, mismo que de manera literal expone:

XII. Toda empresa agrícola, industrial, minera o de cualquier otra clase de trabajo, estará obligada, según lo determinen las leyes reglamentarias a proporcionar a los trabajadores habitaciones cómodas e higiénicas. Esta obligación se cumplirá mediante las aportaciones que las empresas hagan a un fondo nacional de la vivienda a fin de constituir depósitos en favor de sus trabajadores y establecer un sistema de financiamiento que permita otorgar a éstos crédito barato y suficiente para que adquieran en propiedad tales habitaciones. Se considera de utilidad social la expedición de una ley para la creación de un organismo integrado por representantes del Gobierno Federal, de los trabajadores y de los patrones, que administre los recursos del fondo nacional de la vivienda.

Dicha ley regulará las formas y procedimientos conforme a los cuales los trabajadores podrán adquirir en propiedad las habitaciones antes mencionadas. Las negociaciones a que se refiere el párrafo primero de esta fracción, situadas fuera de las poblaciones, están obligadas a establecer escuelas, enfermerías y demás servicios necesarios a la comunidad.

Además, en esos mismos centros de trabajo, cuando su población exceda de doscientos habitantes, deberá reservarse un espacio de terreno, que no será menor de cinco mil metros cuadrados, para el establecimiento de mercados públicos, instalación de edificios destinados a los servicios municipales y centros recreativos.

Queda prohibido en todo centro de trabajo, el establecimiento de expendios de bebidas embriagantes y de casas de juego de azar; NOS).

... (CONSTITUCIÓN POLIITICA DE LOS ESTADOS UNIDOS MEXICA-

Además, en lo que refiere a su base reglamentaria, se encuentra legislada por la Ley Federal del Trabajo, dentro del Capítulo III, denominado de las "Habitaciones para los Trabajadores», apartado que comprende de los artículos 136 al 15317, así como la Ley del Instituto

17 El contenido de la Ley Federal del Trabajo, dentro su CAPITULO III. Habitaciones para los Trabajadores, comprende los siguientes numerales:

Artículo 136. Toda empresa agrícola, industrial, minera o de cualquier otra clase de trabajo, está obligada a proporcionar a los trabajadores habitaciones cómodas e higiénicas. Para dar cumplimiento a esta obligación, las empresas deberán aportar al Fondo Nacional de la Vivienda el cinco por ciento sobre los salarios de los trabajadores a su servicio. 
Artículo 137. El Fondo Nacional de la Vivienda tendrá por objeto crear sistemas de financiamiento que permitan a los trabajadores obtener crédito barato y suficiente para adquirir en propiedad habitaciones cómodas e higiénicas, para la construcción, reparación, o mejoras de sus casas habitación y para el pago de pasivos adquiridos por estos conceptos.

Artículo 138. Los recursos del Fondo Nacional de la Vivienda serán administrados por un organismo integrado en forma tripartita por representantes del Gobierno Federal, de los trabajadores y de los patrones.

Artículo 139. La ley que cree dicho organismo regulará los procedimientos y formas conforme a los cuales los trabajadores podrán adquirir en propiedad habitaciones y obtener los créditos a que se refiere el artículo 137.

Artículo 140. El organismo a que se refieren los artículos 138 y 139, tendrá a su cargo la coordinación y el financiamiento de los programas de construcción de casas habitación destinadas a ser adquiridas en propiedad por los trabajadores.

Artículo 141. Las aportaciones al Fondo Nacional de la Vivienda son gastos de previsión social de las empresas y se aplicarán en su totalidad a constituir depósitos en favor de los trabajadores que se sujetarán a las bases siguientes: I. En los casos de incapacidad total permanente, de incapacidad parcial permanente, cuando ésta sea del $50 \%$ o más; de invalidez definitiva, en los términos de la Ley del Seguro Social; de jubilación; o de muerte del trabajador, se entregará el total de los depósitos constituidos, a él o sus beneficiarios, con una cantidad adicional igual a dichos depósitos, en los términos de la Ley, a que se refiere el artículo 139; II. Cuando el trabajador deje de estar sujeto a una relación de trabajo y cuente con 50 o más años de edad, tendrá derecho a que se le haga entrega del total de los depósitos que se hubieren hecho a su favor, en los términos de la Ley del Instituto del Fondo Nacional de la Vivienda para los Trabajadores; III. En caso de que el trabajador hubiere recibido crédito del Instituto, las cantidades a que tuviere derecho en los términos de las fracciones anteriores, se aplicarán a la amortización del crédito, salvo en los casos de incapacidad total permanente o de muerte, en los términos del artículo 145 si después de hacer la aplicación de dichas cantidades a la amortización del crédito quedare saldo a favor del trabajador se le entregará a éste el monto correspondiente. Para la devolución de los depósitos y cantidades adicionales bastará que la solicitud por escrito se acompañe con las pruebas pertinentes.

Artículo 142. Cuando una empresa se componga de varios establecimientos, la obligación a que se refiere el Artículo 136 de esta ley se extiende a cada uno de ellos y a la empresa en su conjunto.

Artículo 143. Para los efectos de este Capítulo el salario a que se refiere el artículo 136 se integra con los pagos hechos en efectivo por cuota diaria, y las gratificaciones, percepciones, alimentación, habitación, primas, comisiones, prestaciones en especie y cualquier otra cantidad o prestación que se entregue al trabajador por sus servicios; no se tomarán en cuenta dada su naturaleza, los siguientes conceptos: a) Los instrumentos de trabajo, tales como herramientas, ropa y otros similares; b) El ahorro, cuando se integre por un depósito de cantidad semanaria o mensual igual del trabajador y de la empresa; y las cantidades otorgadas por el patrón para fines sociales o sindicales; c) Las aportaciones al Instituto de Fondo Nacional de la Vivienda para los Trabajadores y las participaciones en las utilidades de las empresas; d) La alimentación y la habitación cuando no se proporcionen gratuitamente al trabajador, así como las despensas; e) Los premios por asistencia; f) Los pagos por tiempo extraordinario, salvo cuando este tipo de servicios esté pactado en forma de tiempo fijo; g) Las cuotas al Instituto Mexicano del Seguro Social a cargo del trabajador que cubran las empresas.

Artículo 144. Se tendrá como salario máximo para el pago de las aportaciones el equivalente a diez veces el salario mínimo general del área geográfica de aplicación que corresponda.

Artículo 145. Los créditos que se otorguen por el organismo que administre el Fondo Nacional de la Vivienda, estarán cubiertos por un seguro, para los casos de incapacidad total permanente o de muerte, que libere al trabajador o a sus beneficiarios de 
las obligaciones, gravámenes o limitaciones de dominio a favor del citado organismo, derivadas de esos créditos.

Para tales efectos, se entenderá por incapacidad total permanente la pérdida de facultades o aptitudes de una persona, que la imposibiliten para desempeñar cualquier trabajo por el resto de su vida, cualquiera que sea la naturaleza del riesgo que la haya producido.

Tratándose de los casos de incapacidad parcial permanente, cuando ésta sea del 50\% o más, o invalidez definitiva, se liberará al trabajador acreditado del adeudo, los gravámenes o limitaciones de dominio a favor del Instituto, siempre y cuando no sea sujeto de una nueva relación de trabajo por un período mínimo de dos años, lapso durante el cual gozará de una prórroga sin causa de intereses, para el pago de su crédito. La existencia de cualquiera de estos supuestos deberá comprobarse ante el Instituto del Fondo Nacional de la Vivienda para los Trabajadores, dentro del mes siguiente a la fecha en que se determinen.

Artículo 146. Los patrones no estarán obligados a pagar las aportaciones a que se refiere el Artículo 136 de esta ley por lo que toca a los trabajadores domésticos.

Artículo 147. El Ejecutivo Federal, previo estudio y dictamen del organismo que se constituya para administrar los recursos del Fondo Nacional de la Vivienda, determinará las modalidades y fechas en que incorporarán al régimen establecido por este capítulo: I. Los deportistas profesionales y II. Los trabajadores a domicilio.

Artículo 148. El Ejecutivo Federal podrá establecer modalidades para facilitar la aportación de las empresas que tengan un capital o un ingreso inferior a los mínimos que el propio Ejecutivo determine. Estas resoluciones podrán revisarse total o parcialmente cuando a su juicio existan circunstancias que lo justifiquen.

Artículo 149. El organismo que se cree para administrar los recursos del Fondo Nacional de la Vivienda, determinará las sumas que se asignarán al financiamiento de programas de casas habitación destinadas a ser adquiridas en propiedad por los trabajadores y los que se aplicarán para la adquisición, construcción, reparación o mejoras de dichas casas, así como para el pago de pasivos adquiridos por estos conceptos.

Al efectuar la aplicación de recursos, se distribuirán equitativamente entre las distintas regiones y localidades del país, así como entre las diversas empresas o grupos de trabajadores.

Para el otorgamiento individual de los créditos se procederá en caso necesario conforme a un sistema de sorteos, en los términos que establezca la ley a que se refiere el artículo 139.

Artículo 150. Cuando las empresas proporcionen a sus trabajadores casa en comodato o arrendamiento no están exentas de contribuir al Fondo Nacional de la Vivienda, en los términos del artículo 136. Tampoco quedarán exentas de esta aportación respecto de aquellos trabajadores que hayan sido favorecidos por créditos del fondo.

Artículo 151. Cuando las habitaciones se den en arrendamiento a los trabajadores, la renta no podrá exceder del medio por ciento mensual del valor catastral de la finca y se observarán las normas siguientes: I. Las empresas están obligadas a mantenerlas en condiciones de habitabilidad y a hacer oportunamente las reparaciones necesarias y convenientes; II. Los trabajadores tienen las obligaciones siguientes: a) Pagar las rentas; b) Cuidar de la habitación como si fuera propia; c) Poner en conocimiento de la empresa los defectos o deterioros que observen; d) Desocupar las habitaciones a la terminación de las relaciones de trabajo dentro de un término de cuarenta y cinco días y III. Está prohibido a los trabajadores: a). Usar la habitación para fines distintos de los señalados en este capítulo; b) Subarrendar las habitaciones.

Artículo 152. Los trabajadores tendrán derecho a ejercitar ante las Juntas de Conciliación y Arbitraje las acciones individuales y colectivas que deriven del incumplimiento de las obligaciones impuestas en este capítulo.

Artículo 153. Las empresas tendrán derecho a ejercitar ante las Juntas de Conciliación y Arbitraje, las acciones que les correspondan en contra de los trabajadores por incumplimiento de las obligaciones que les impone este capítulo. 
del Fondo Nacional de la Vivienda para los Trabajadores (INFONAVIT), misma que en su artículo $3 .^{\circ}$ prevé que el objeto del Instituto consiste en:

Artículo 3. ${ }^{\circ}$. El Instituto tiene por objeto:

I. Administrar los recursos del Fondo Nacional de la Vivienda;

II. Establecer y operar un sistema de financiamiento que permita a los trabajadores obtener crédito barato y suficiente para:
a) La adquisición en propiedad de habitaciones cómodas e higiénicas,
b) La construcción, reparación, ampliación o mejoramiento de sus habitaciones, y
c) El pago de pasivos contraídos por los conceptos anteriores;

III. Coordinar y financiar programas de construcción de habitaciones destinadas a ser adquiridas en propiedad por los trabajadores; y

IV. Lo demás a que se refiere la fracción XII del Apartado A del Artículo 123 Constitucional y el Título Cuarto, Capítulo III de la Ley Federal del Trabajo, así como lo que esta ley establece. (LEY DEL INSTITUTO DEL FONDO NACIONAL DE LA VIVIENDA PARA LOS TRABAJADORES).

Ahora bien, respecto de las aportaciones que las sociedades cooperativas deben cubrir obligatoriamente al Instituto del Fondo Nacional de la Vivienda para los Trabajadores (INFONAVIT), dentro de las fracciones I y II de la Ley del INFONAVIT, se prevé que «los patrones tienen la obligación de inscribir a sus trabajadores al Instituto, y pagar las aportaciones del cinco por ciento sobre el salario de sus empleados». (PÉREZ y Fol, 2012: 413)18.

18 La Ley del Instituto del Fondo Nacional de la Vivienda para los Trabajadores (INFONAVIT), establece en su artículo 29. "Son obligaciones de los patrones: I. Proceder a inscribirse e inscribir a sus trabajadores en el Instituto y dar los avisos a que se refiere el Artículo 31 de esta Ley. Los patrones estarán obligados, siempre que contraten un nuevo trabajador, a solicitarle su número de Clave Única de Registro de Población. Los patrones inscribirán a sus trabajadores con el salario que perciban al momento de su inscripción; II. Determinar el monto de las aportaciones del cinco por ciento sobre el salario de los trabajadores a su servicio y efectuar el pago en las entidades receptoras que actúen por cuenta y orden del Instituto, para su abono en la subcuenta de vivienda de las cuentas individuales de los trabajadores previstas en los sistemas de ahorro para el retiro, en los términos de la presente Ley y sus reglamentos, así como en lo conducente, conforme a lo previsto en la Ley del Seguro Social y en la Ley Federal del Trabajo. En lo que corresponde a la integración y cálculo de la base y límite superior salarial para el pago de aportaciones, se aplicará lo contenido en la Ley del Seguro Social. Estas aportaciones son gastos de previsión de las empresas y forman parte del patrimonio de los trabajadores. Los pa- 
De ahí que las sociedades cooperativas, tengan la obligación de pagar las aportaciones al Fondo Nacional de la Vivienda para los Trabajadores, respecto de los asalariados que les presten un servicio personal subordinado en términos de lo previsto por la Ley Federal el Trabajo en sus artículos 20 y 21, así como de los numerales 12 y 15 de la Ley del Seguro Social ${ }^{19}$, además de los arábigos $1 .^{\circ}$, párrafo primero y $2 .^{\circ}$, fracción II del Código Fiscal de la Federación, mismos que a la letra señalan:

Artículo 1.․ Las personas físicas y las morales, están obligadas a contribuir para los gastos públicos conforme a las leyes fiscales respectivas. Las disposiciones de este Código se aplicarán en su defecto y sin perjuicio de lo dispuesto por los tratados internacionales de los que México sea parte. Sólo mediante ley podrá destinarse una contribución a un gasto público específico.

Artículo $2^{\circ}$. Las contribuciones se clasifican en impuestos, aportaciones de seguridad social, contribuciones de mejoras y derechos, las que se definen de la siguiente manera:

II. Aportaciones de seguridad social son las contribuciones establecidas en ley a cargo de personas que son sustituidas por el Estado en el cumplimiento de obligaciones fijadas por la ley en materia de seguridad social o a las personas que se beneficien en forma especial por servicios de seguridad social proporcionados por el mismo Estado.

... (CÓDIGO FISCAL DE LA FEDERACIÓN).

No obstante, que el precepto legal del artículo 29 de la Ley del INFONAVIT, "... no aplica en el caso de los socios de sociedades cooperativas - de consumo-, ya que éstas no utilizan los servicios de sus

trones, al realizar el pago, deberán proporcionar la información relativa a cada trabajador en la forma y con la periodicidad que al efecto establezca la presente Ley y, en lo aplicable, la Ley del Seguro Social y la Ley de los Sistemas de Ahorro para el Retiro. El registro sobre la individualización de los recursos de la subcuenta de vivienda de las cuentas individuales de los sistemas de ahorro para el retiro, estará a cargo de las administradoras de fondos para el retiro, en los términos que se establecen en la Ley de los Sistemas de Ahorro para el Retiro y su Reglamento. Lo anterior, independientemente de los registros individuales que determine llevar el Instituto. Es obligación del patrón pagar las aportaciones por cada trabajador mientras exista la relación laboral y subsistirá hasta que se presente el aviso de baja correspondiente. Si se comprueba que dicho trabajador fue inscrito por otro patrón, el Instituto devolverá al patrón omiso, a su solicitud, el importe de las aportaciones pagadas en exceso, a partir de la fecha de la nueva alta; ...»

19 Los artículos 20 y 21 de la Ley Federal del Trabajo, así como los numerales 12 y 15 de la Ley del Seguro Social, se muestran dentro de los apartados 3.1. y 3.2. de esta investigación, motivo por el cual sería repetitivo y reiterativo desglosar su contenido. 
miembros o socios en forma subordinada (...) por lo que al no reunir la calidad de trabajadores, las sociedades no tienen la obligación de pagar las aportaciones habitacionales del cinco por ciento respecto de las personas que asuman el carácter de trabajadores por no prestar un servicio personal subordinado» (PÉREZ y Fol, 2012: 414), tal como se establece en el criterio número 46 emitido por el Instituto del Fondo Nacional de la Vivienda para los Trabajadores (INFONAVIT), y desde luego por no constituirse como trabajadores según lo previsto por el artículo 8. ${ }^{\circ}$ de la Ley Federal del Trabajo.

Refuerza el criterio número 46 emitido por el INFONAVIT, la Tesis de Jurisprudencia 178/2007, misma que a continuación se transcribe 20 :

\section{SOCIEDADES COOPERATIVAS. DEBEN CUBRIR AL INFONAVIT LAS APORTACIONES DE SUS TRABAJADORES, NO ASÍ DE SUS SOCIOS COOPERATIVISTAS.}

El artículo 123, apartado A, fracción XII, de la Constitución Política de los Estados Unidos Mexicanos establece el derecho de los trabajadores de obtener, por parte del patrón, habitaciones cómodas e higiénicas, lo que se considera una garantía de previsión social que deberá cumplirse mediante las aportaciones efectuadas por las empresas al fondo nacional de la vivienda y que constituyen depósitos en favor de sus trabajadores, y también dispone un sistema de financiamiento que permita otorgar a éstos crédito barato y suficiente para adquirir en propiedad tales habitaciones. Ahora bien, dicho precepto, en relación con el artículo 57 de la Ley General de Sociedades Cooperativas y la Ley del Seguro Social, ubica a las sociedades cooperativas dentro de las normas que se relacionan, por una parte, con la seguridad social, en tanto que dichas sociedades tienen el deber jurídico de cubrir la cuota del seguro social correspondiente a los patrones por los trabajadores que tengan, además de incorporar a sus socios cooperativistas al aseguramiento del régimen obligatorio y, por la otra, con la solidaridad social, en la medida en que, si bien no se les impone el deber de cubrir al Instituto del Fondo Nacional de la Vivienda para los Trabajadores las aportaciones de vivienda correspondientes a sus socios cooperativistas, sí lo deberán efectuar, en su carácter de patrón, respecto de sus trabajadores. ${ }^{21}$

20 Cfr. Amparo en revisión 1977/2006, de 28 de marzo de 2007; Amparo en revisión 379/2007, de 13 de junio de 2007; Amparo en revisión 343/2007, de 15 de agosto de 2007; Amparos en revisión 423/2007 y 425/2007, ambos de fecha 15 de agosto de 2007; Todos consultables en el Semanario Judicial de la Federación y su gaceta, Novena época. Tomo XXVI. Septiembre de 2007. p. 555.

21 Tesis de jurisprudencia 178/2007. Aprobada por la Segunda Sala de la Suprema Corte de Justicia de la Nación (SCJN), en sesión privada del veintinueve de agosto de dos mil siete. Registro 171286 


\section{Conclusión}

El artículo $8^{\circ}$ de la Ley Federal del Trabajo, indica que trabajador es la persona física, que presta a otra física o moral un trabajo personal subordinado, y el artículo 20 de la Ley General de Sociedades Cooperativas señala que la sociedad cooperativa es una forma de organización integrada por personas físicas, las cuales aportan sus servicios personales en su calidad de socios y no de trabajadores, no obstante de que tienen la posibilidad de llevar a cabo la contratación laboral de personal en términos de lo que establece el propio artículo 20 de la Ley Federal del Trabajo.

Lo anterior, permite que para efectos de los sujetos de protección en materia de seguridad social, la fracción II del artículo 12 de la Ley del Seguro Social, prevé que son sujetos de aseguramiento al régimen obligatorio del Seguro Social los socios de sociedades cooperativas, sin dejar de lado la obligatoriedad que deben cumplir en su carácter de empleadores ante el Instituto Mexicano del Seguro Social (IMSS) en términos de los previsto por el artículo 15 de la misma Ley del Seguro Social, así como el deber de afiliar y pagar sus aportaciones ante el Instituto del Fondo Nacional de la Vivienda para los Trabajadores (INFONAVIT).

De lo anterior, se ha precisado que el propio artículo 19 de la Ley del Seguro Social señala que las sociedades cooperativas en su calidad de agrupación en general pagarán la cuota correspondiente a los patrones, y cada uno de los socios cooperativistas en particular tendrán que cubrir sus cuotas como trabajadores, constituyendo de esta manera una aportación bipartita. Sin embargo, si la cooperativa lleva a cabo contratación de personal, deberá además, obligarse como empleador o patrono al pago de la cuota patronal, concertando así una aportación de tipo tripartita.

En virtud de ello, los artículos 28-A de la Ley del Seguro Social y 51 del Reglamento de la Ley del Seguro Social en materia de Afiliación, Clasificación de Empresas, Recaudación y Fiscalización, estipulan que la base de cotización de los socios cooperativistas se integrará por el total de las percepciones que reciban por las aportaciones de su trabajo personal, siéndoles aplicables las mismas reglas generales de límites de salario base de cotización de determinación de la base salarial22 y periodo de cotización.

Por lo que toca al Instituto del Fondo Nacional de la Vivienda para los Trabajadores (INFONAVIT), el criterio jurídico número 46 emitido por esta Institución, señala que las sociedades cooperativas no tienen la

22 Los límites inferior y superior del Salario Base de Cotización van de 1 hasta 25 veces el Salario Mínimo General vigente en el Distrito Federal, límites que se encuentran previstos en el contenido del artículo 28 de la Ley del Seguro Social. 
obligación de retener mensualmente, ni de enterar de manera bimestral el cinco por ciento por concepto de aportaciones habitacionales por sus socios, en virtud de que estos no son trabajadores de acuerdo con lo mencionado en el artículo $8 .^{\circ}$ de la Ley Federal del Trabajo, situación que cambia al momento en que la sociedad cooperativa contrata laboralmente a personal, deduciéndose por ende, que esta obligación de la retención y pago de cuota habitacional pasa a ser obligatoria para la sociedad cooperativa en su carácter de empleador o patrón.

\section{Fuentes de consulta}

\section{a) Bibliográfica}

ALCARÁZ de la Rosa, José. (2009). Ley del Seguro Social Comentada. México. PAC.

BREÑA Garduño, Francisco. (2013). Ley Federal del Trabajo. Comentada y Concordada. México. OXFORD.

CABANELLAS, Guillermo. (1968). Compendio de Derecho Laboral. Tomo I. Buenos Aires, Argentina. BIBLIOGRAFÍA OMEBA.

MORENO Padilla, Javier. (2010). Nueva Ley del Seguro Social. 2. ${ }^{a}$ ed. México. TRILLAS.

PÉREZ ChÁvEZ, José y Raymundo Fol Olguín. (2012). Sociedades Cooperativas. Tratamiento fiscal y de seguridad social. México. TAX.

b) Hemerográfica

ONG Contraloría Ciudadana para la Rendición de Cuentas, A.C. (Octubre 2009). Manual para la Constitución y Administración de Sociedades Cooperativas Comunitarias. México. ONG.

c) Legislativas

- Constitución Política de los Estados Unidos Mexicanos

- Ley General de Sociedades Mercantiles

- Ley General de Sociedades Cooperativas

- Código Fiscal de la Federación

- Ley Federal del Trabajo

- Ley del Seguro Social

- Reglamento de la Ley del Seguro Social en Materia de Afiliación, Clasificación de Empresas, Recaudación y Fiscalización 
d) Electrónicas

- https://www.scjn.gob.mx/Paginas/Inicio.aspx

— http://200.38.163.178/SJFSem/Paginas/Semanariolndex.aspx

- http://www.imss.gob.mx/Pages/index.aspx

- http://portal.infonavit.org.mx/wps/wcm/connect/infonavit/inicio 


\section{Derechos de autor}

La revista Deusto Estudios Cooperativos es una revista de acceso abierto lo que significa que es de libre acceso en su integridad inmediatamente después de la publicación de cada número. Se permite su lectura, la búsqueda, descarga, distribución y reutilización legal en cualquier tipo de soporte sólo para fines no comerciales y según lo previsto por la ley; sin la previa autorización de la Editorial (Universidad de Deusto) o el autor, siempre que la obra original sea debidamente citada (número, año, páginas y DOI si procede) y cualquier cambio en el original esté claramente indicado.

\section{Copyright}

The Deusto Journal of Cooperative Studies is an Open Access journal which means that it is free for full and immediate access, reading, search, download, distribution, and lawful reuse in any medium only for non-commercial purposes, without prior permission from the Publisher or the author; provided the original work is properly cited and any changes to the original are clearly indicated. 